\title{
Regional anesthesia technique for carotid surgery
}

T. Gramosli; N Hristov; D. Vuckova; M. Gjorgon; D. Popevski; E. Stoicovski; Z. Mitrev Zan Mitrev Clinic, Skopje, Republic of North Macedonia

Background: The decision for general anesthesia (GA) vs regional anesthesia (RA) for staged carotid endarterectomy (CEA) is an ongoing debate $[1,2]$. Should be done on an individual basis [3].

We present a case of a highly-comorbid patient with dilated cardiomyopathy (DCM) undergoing staged CEA using RA.

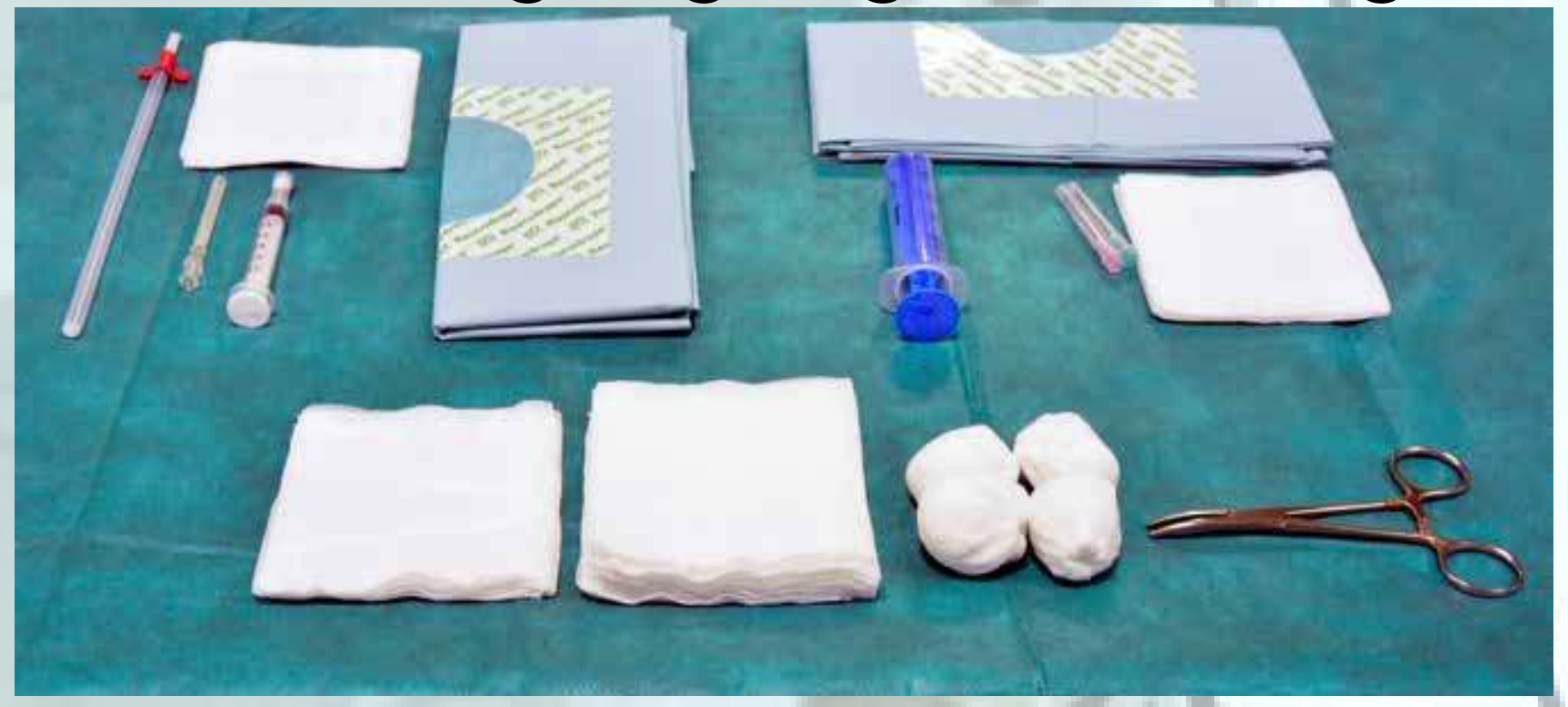

Case report: A 72-year-old patient with previous stroke and soft carotid bifurcation plaque was admitted for right CEA. He experienced an infarction 4 years ago, left untreated, thus developing dilated cardiomyopathy, diabetic with an GFR of $43.7 \mathrm{~mL} / \mathrm{min} / 1.73 \mathrm{~m}^{2}$. Preoperative evaluation showed dyspnea at rest NYHA IV; and intermittent chest pain CCS IV. We opted for staged CEA shortly followed by coronary revascularization. Due to minimal invasiveness, RA was chosen because of the high-risk of myo- cardial infarction, intraoperative stroke and renal insufficiency. Deep cervical plexus block was performed, from C2 to C4 using $10 \mathrm{ml} \mathrm{0,5 \%} \mathrm{bupivacaine} \mathrm{and}$ $10 \mathrm{ml} \mathrm{1 \%}$ lidocaine [4]. Surgery was uneventful, pain free, with stable hemodynamics, using eversion endarterectomy and no shunt.


Postoperative recovery was uneventful, patient was discharged on the $2^{\text {nd }}$ day following surgery.

Conclusion: Staged CEA in high risk coronary patients can be safely performed using minimal invasive RA. Our ongoing study for RA vs GA in this patient will give definitive answer.

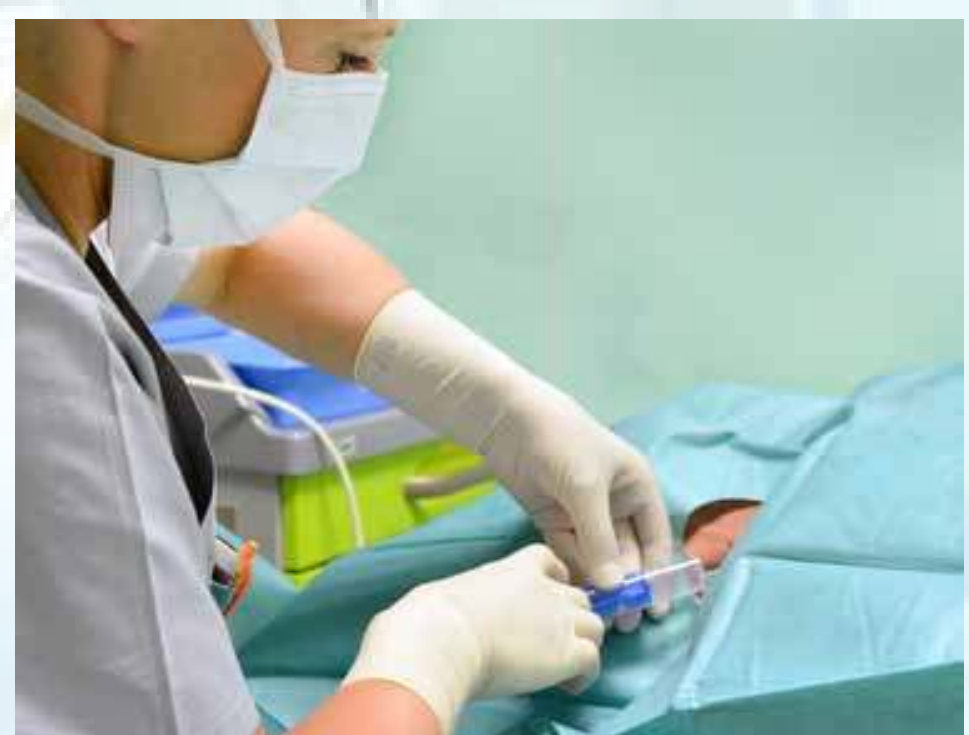

\section{References:}

1. Unic-Stojanovic D, Jovic M: Local anaesthesia for carotid endarterectomy: Con: decrease the stress for all. Eur J Anaesthesiol 2016, 33(4):238-240.

2. Cedergreen $P$, Swiatek F, Nielsen HB: Local anaesthesia for carotid endarterectomy: Pro: protect the brain. Eur J Anaesthesiol 2016, 33(4):236-237.

3. Group GTC, Lewis SC, Warlow CP, Bodenham AR, Colam B, Rothwell PM, Torgerson D, Dellagrammaticas D, Horrocks M, Liapis C et al: General anaesthesia versus local anaesthesia for carotid surgery (GALA): a multicentre, randomised controlled trial. Lancet 2008, 372(9656):2132-2142.

4. Masters RD, Castresana EJ, Castresana MR: Superficial and deep cervical plexus block: technical considerations. AANA J 1995, 63(3):235-243. 